\title{
Brazilian Association of Pharmaceutical Sciences
}

We are now approaching the end of one more year, and with it the term of the current administrative committee of the Brazilian Association of Pharmaceutical Sciences (ABCF) comes to a conclusion. The 20122013 administrative committee for ABCF was elected last August. At that moment, the accomplishments from the last two years were reviewed, and new goals for the next two-year term were set. Among these goals, the organization of an annual meeting of $\mathrm{ABCF}$, the nomination of regional representatives to facilitate the communication between the administrative committee and ABCF members, and co-sponsorship of regional events should be highlighted.

The creation of ABCF in 2003 results from innumerous discussions among faculty and directors of pharmaceutical sciences graduate programs regarding the need for a scientific association to represent the field, and interface with sponsoring agencies and other scientific associations. To cite a few of ABCF goals, this association aims at meeting the priorities of the Brazilan's health care system, as well as acting synergistically with other scientific associations to promote the development of science, technology and innovation, to reduce differences on the level of scientific development among various country regions and to strengthen selected strategic areas. Many of these goals have been met, but new ones require that we focus and continue to work together.

The growth and strengthening of the pharmaceutical sciences field over the past years are expressed by the increase in the number of graduate programs recommended by CAPES (a total of 49) and of undergraduate programs spread throughout the country (over 400). These programs count with more than 700 full-time faculty, at least 2000 graduate students and 12000 undergraduate students. Based on this large number of participants in the field, it is fair to believe - and expect - that together we can build a stronger and more expressive ABCF. We need the support of everyone in the pharmaceutical sciences field to grow. Support $\mathrm{ABCF}$ and become a member.

The 2010-2011 administrative committee of ABCF would like to take this opportunity to thank all the support received and to wish all of you - especially the new administrative committee - happy Holidays and a new year filled with happiness and success.

João Luis Callegari Lopes

President of Brazilian Association of Pharmaceutical Sciences www.abcfarm.org.br 
